\title{
Entre tradición y modernidad: modificaciones del poema litánico en la poesía de Juan Ramón Jiménez
}

\author{
Maria Judyta Woźniak ${ }^{1}$
}

Published online: 1 August 2016

(C) The Author(s) 2016. This article is published with open access at Springerlink.com

\begin{abstract}
Litanic verse, older than the literatures of Europe, has become an important and coherent versification structure. However, in Spanish-language literature the poetic litany of the eighteenth and nineteenth centuries was not very productive: various types of repetitiveness are common devices in the literature but they are seldom of a litanic nature. Nevertheless, from the beginning of Modernism it was a creative inspiration to many poets. The main objective of this article is to present various interpretive options that litanic poetics brings in poems by Juan Ramón Jiménez based on an analysis of stylistic devices. The Spanish poet transforms the centuries-old tradition of poetic litany as a genre deeply rooted in the Christian tradition. It serves as a way to express subjective and sensual meanings: if God (or a god) is its addressee, he does not correspond to Christian images; to express the disintegration of one's own identity; to attribute divine features to the human and poetic art; or to express the uniqueness of a moment, place, feeling. It is only when the continuity in the litany genre development is noticed it is possible to see modifications of the meaning and function of the litanic genre, departure from a prayer-like nature, the closest one to the genre pattern, for the sake of expressing what is human and individual.
\end{abstract}

Keywords Litanic verse · Juan Ramón Jiménez · Spanish poetry · Poetics

El artículo se ha realizado en el marco del proyecto de investigación "El poema litánico en la cultura de las regiones de Europa". El proyecto ha sido financiado por el Centro Nacional de la Ciencia de Polonia, con la subvención $\mathrm{n}^{\circ}$ DEC-2012/07/E/HS2/00665.

Maria Judyta Woźniak

judytawo@gmail.com

1 Departamento de Filología Española, Universidad de Lodz, Lodz, Poland 
A partir de finales del siglo XIX las referencias a la poética litánica en la poesía española se hacen sorprendentemente frecuentes. ${ }^{1}$ Aunque las repeticiones, en general, en la poesía española siempre habían sido abundantes, a partir del modernismo adquieren más a menudo un carácter litánico y a la vez, en muchos casos, se convierten en un modo de expresión importante para los poetas. Asimismo las realizaciones poéticas del poema litánico presentan varios tipos de modificaciones, de acuerdo con el espíritu de la época.

Hasta finales del siglo XIX, los poetas, en su mayoría, usan elementos litánicos de manera bastante convencional (por ejemplo, Diego de Torres Villarroel). Los poemas que podemos llamar letanías poéticas suelen imitar el modelo del género, ${ }^{2}$ tradicionalmente de carácter de oración. ${ }^{3}$ Sin embargo, en el siglo XIX aparecen cada vez más realizaciones alejadas de la visión cristiana del mundo, arraigada en la historia del género (por ejemplo, algunos poemas de José Zorilla y Gertrudis Gómez de Avellaneda en los que las perífrasis describen a un hombre o algún concepto, y no a $\operatorname{Dios}^{4}$ ).

A finales del siglo XIX el sujeto poético de los poemas litánicos se dirige cada vez menos a Dios y a los santos. Así los poetas se oponen a la visión tradicional del mundo que conlleva dicho género, relacionado con la oración cristiana del hombre lleno de humillación a Dios todopoderoso. Las realizaciones de la poética litánica, que de distintas formas modifican el modelo, aparecen, pues, cuando el sujeto lírico muestra sus rasgos individuales cada vez más directamente. En vez de aceptar la visión del mundo del cristianismo, el yo poético es consciente de la complejidad de la realidad y de su ambigüedad: habla de lo desconocido de la esencia de las cosas, de las dificultades que tiene para definir su propia identidad. En esos intentos de entender el mundo y a sí mismo, el poema litánico como género literario resultó ser un recurso importante, convirtiéndose en un modo de expresión poética muy adecuado en la época de la crisis modernista, que a menudo significaba una crisis religiosa. ${ }^{5}$

\footnotetext{
${ }^{1}$ Fradejas Lebrero, un crítico que ha dedicado mucha atención a lo que él mismo ha llamado "forma litánica", afirma con certeza que este tipo de poética adquiere mucha importancia en la obra literaria del siglo XX (Fradejas Lebrero 1996: 399). El mismo autor ve la realización de la poética litánica especialmente en la obra de Juan Ramón Jiménez. Sobre la forma litánica en la poesía española véase también Fradejas Lebrero (1981, 1988).

${ }^{2}$ Entre la prosa de Diego de Torres Villarroel encontramos algunos poemas litánicos. Citemos unos versos de uno de ellos (Torres Villarroel 1798: 210-211): "Jesús amoroso,/Amante divino,/objeto del alma:/No desprecies, Señor, mis suspiros". El último verso se repite como cuarto verso de todas las estrofas. Las súplicas y antonomasias se usan aquí para pedir piedad a Dios en una oración sumisa y humillada.
}

${ }^{3}$ Recordemos que la letanía como oración siempre había sido poética, por ejemplo, gracias a un gran número de recursos poéticos. Más sobre el tema, véase Sadowski (2011: 10, 194).

${ }^{4}$ Cf. por ejemplo J. Zorrilla, María cuyo nombre, donde el hombre se dirige a la Virgen que es para él la fuente de inspiración poética; G. G. de Avellaneda, A mi amigo Zorrilla, donde las perífrasis se refieren a un hombre y no a Dios ni a sus santos.

${ }^{5}$ Otros poetas de fin de siglo y de las primeras décadas del siglo XX que recurrieron al poema litánico fueron, por ejemplo, Miguel de Unamuno, Ramón María del Valle-Inclán, Gerardo Diego, Federico García Lorca, Miguel Hernández. Es interesante que el género de letanía se convierta en un modo de expresión tan frecuente a partir de finales del siglo XIX, en la época de la crisis espiritual que se puede considerar como verdadero punto crucial de la modernidad finisecular (Fiore 2012: 494). Recordemos 
¿Qué sería, pues, el poema litánico? Fradejas Lebrero, un crítico que se ha dedicado a estudiar en la literatura española lo que él mismo ha llamado "la forma litánica", propone el estribillo como elemento distintivo de dicha forma (Fradejas Lebrero 1996: 399). Este tipo de repetitividad es propia de la poesía desde sus orígenes relacionados con la música, así que no parece suficiente para definir el género. ${ }^{6}$ Sin duda alguna, su poética se caracteriza por los recursos estilísticos propios de ella y lo son especialmente los que están relacionados con la repetitividad, como, por ejemplo, el paralelismo sintáctico, las anáforas, las antonomasias o las perífrasis (véase Sadowski 2011: 28). Además, proponemos otros rasgos distintivos, refiriéndonos a la historia del género.

En el género que llamamos poema litánico vemos la continuación de una tradición literaria que en su origen tuvo por lo menos tres genes. El concepto de los genes, arraigados en la tradición de la poética litánica, proporciona herramientas más precisas para describir dicha poética y su significado. Según su autor, Witold Sadowski, serían: el gen polionímico (del griego polyónymos: que tiene muchos nombres, se aplicaba solo a los dioses de mayor autoridad), el gen relacionado con el griego "chaire" (aparte del griego "chaire" también, por ejemplo, "salve", "ave" y sus equivalentes) y el gen ektenial (por ejemplo, formas diferentes de pedir misericordia; el término viene de los ektenia, géneros litúrgicos). ${ }^{7}$ De los tres, el

\begin{abstract}
Footnote 5 continued
también que en muchos países europeos tuvo mucho impacto el poema de Baudelaire Les litanies de Satan, que empleaba la poética del género litánico al revés, de forma blasfema (lo podemos observar, por ejemplo, en el estribillo: "O Satan, prends pitié de ma longue misère!"). Sobre la recepción del poeta francés en España, véase, por ejemplo, Hambrook (1985), Marín Hernández (2007), Medina Arjona (2009). En español, su obra no se publicó hasta el año 1894. El escritor que se interesó más profundamente por la poesía de Baudelaire fue Juan Valera, en 1886. Con más perspicacia lo leyó Clarín (Leopoldo Alas), a quien atrajo la espiritualidad cristiana y el simbolismo del mal. Gracias a él, Juan Ramón Jiménez conoció la poesía del poeta francés.

6 Así, Fradejas Lebrero cita el poema Renaceré yo como ejemplo de poética litánica. En su opinión, su estructura constituye una variante significativa importante, cultísima, que se distingue de la forma litánica en sus orígenes. Aquí cambia solo el primer verso, el segundo se repite:
\end{abstract}

Renaceré yo piedra, y aún te amaré mujer a ti.

Renaceré yo viento, y aún te amaré mujer a ti.

(...)

Renaceré yo hombre, y aún te amaré mujer a ti.

Nosotros, sin embargo, consideramos estas modificaciones como más bien formales, que no parecen aportar cambios significativos en cuanto al sentido. Lo que sí parece probar una tendencia a modificar el modelo del género es el yo como sujeto de nombres polionímicos, en el lugar tradicionalmente destinado a Dios u otro ser supremo.

7 El autor de estos términos, en su versión original en polaco, Witold Sadowski (2011), se sirve del griego porque los elementos de la tradición a la que se refieren tienen su origen en la antigüedad (Sadowski 2011: 25-68). 
polionímico parece especialmente frecuente en la poesía española. En sus orígenes servía para llamar a Dios con varios nombres, ya que su ser permanecía para los hombres desconocido e incomprensible. En cuanto a los recursos estilísticos característicos de la letanía como género literario, como hemos mencionado, son las perífrasis, que suelen describir al receptor, especialmente a Dios y a los santos; las antonomasias, que, a diferencia de las perífrasis, suelen más bien sustituir al nombre del receptor; las anáforas, basadas sobre todo en estructuras sintácticas especiales, como, por ejemplo, "el que...", que se repite a lo largo de todo el poema o de un fragmento. ${ }^{8}$

En la historia del poema litánico español la obra de Juan Ramón Jiménez ocupa un lugar importante. Premio Nobel y uno de los poetas más destacados del modernismo, ${ }^{9}$ Juan Ramón Jiménez buscaba la poesía pura, que reflejara la esencia de las cosas. La forma litánica, en su versión polionímica, responde a este deseo poético, lo que queremos comprobar a continuación en el análisis de los poemas elegidos.

La poesía para Juan Ramón Jiménez, en sus intentos por expresar lo inexpresable, se dirigía hacia la plenitud. Tanto el instinto como la inteligencia, tanto el lenguaje como el silencio son importantes en la creación literaria. Lo que parece interesante es que el poeta buscaba la máxima desnudez, dirigiéndose hacia la trascendencia por la contemplación y apuntando a una invisibilidad de la escritura, que acaba por borrarse a sí misma. Deseando liberarse de las palabras superfluas y abrirse al silencio, pretendía permanecer a la escucha del silencio, anterior al lenguaje. Así, Armando Castro afirma: "Desde Eternidades (1918), libro que sigue al Diario, la evolución de Juan Ramón ha sido precisamente ésta: desnudar el lenguaje para lanzarse a la realidad sin rodeos, sin explicaciones" (López Castro 2006: 180). Como pretendemos demostrar, a esa desnudez, paradójicamente, lo conducía la poética litánica.

El poema litánico, desde sus orígenes relacionado con lo espiritual, también era para el poeta un espacio privilegiado para buscar a Dios, o mejor dicho, a su propio dios -lo escribía con minúscula- a través de la conciencia de lo sagrado. Para Juan Ramón Jiménez, no hay dios superior a la conciencia. El mismo afirmó lo siguiente: "Para mí la poesía ha estado siempre íntimamente fundida con toda mi existencia y no ha sido poesía objetiva casi nunca. Y ¿cómo no había de estarlo en lo místico panteísta la forma suprema de lo bello para mí? No que yo haga poesía relijiosa usual; al revés, lo poético lo considero como profundamente relijioso, esa relijión inmanente sin credo absoluto que yo siempre he profesado" (Jiménez 1981: 170-171). Para escribir tan concebida "poesía relijiosa”, Juan Ramón Jiménez recurre a la poética litánica, desde sus orígenes inmanentemente relacionada con lo religioso, que él mismo transforma según su propia visión del mundo. El poeta, pues, buscando la desnudez del lenguaje, usa la poética litánica, que consiste en repeticiones. Intentando llegar a lo inefable mediante la "poesía pura", se sumerge en la litánica abundancia de palabras.

\footnotetext{
8 Más sobre el tema, véase Sadowski (2011).

9 Sobre las relaciones de Juan Ramón Jiménez con el modernismo véase, por ejemplo, Cardwell (2005).
} 
Nuestro objetivo es mostrar la persistencia de la tradición litánica en sus diferentes variantes, en relación con la propia poética de Juan Ramón Jiménez. Lo vamos a demostrar a través del análisis de los recursos característicos de la letanía poética. Los ejemplos citados, sin pretender ser exhaustivos, muestran su concepto de la poesía, de lo divino y de sí mismo. ${ }^{10}$ Asimismo, muestran los significados esenciales de la poética litánica en la obra del poeta.

En cuanto a la concepción de poesía de Juan Ramón Jiménez es importante el conocido poema en que el autor pide "el nombre esacto de las cosas" (es el poema 419 del tomo Eternidades):

\author{
¡Intelijencia, dame \\ el nombre esacto de las cosas! \\ Que mi palabra sea \\ la cosa misma, \\ creada por mi alma nuevamente. \\ Que por mí vayan todos \\ los que no las conocen, a las cosas; \\ que por mí vayan todos \\ los que ya las olvidan, a las cosas; \\ que por mí vayan todos \\ los mismos que las aman, a las cosas... \\ ¡Intelijencia, dame, \\ el nombre esacto, y tuyo, \\ y suyo, y mío, de las cosas!
}

El yo poético dirige sus apóstrofes y súplicas a la Inteligencia, que cree capaz de otorgarle lo que demanda. De este modo, la Inteligencia parece tener rasgos del Dios todopoderoso. A ella el hombre dirige una serie de peticiones, formuladas a ejemplo de letanía. Así, se repiten las anáforas basadas en las mismas estructuras sintácticas: "que por mí vayan” y "todos los que (...)". Especialmente la última es típica de la letanía: podemos oír aquí el eco de fórmulas litánicas. Por ejemplo, en la Letanía del Santo Nombre de Jesús encontramos frases anafóricas basadas en la misma preposición: "Por tu natividad,/Por tu infancia,/Por tu divinísima vida,/Por tus trabajos,/Por tu agonía y Pasión,/Por tu cruz y desamparo,/Por tus sufrimientos". En las letanías-oraciones, como la aquí citada, estas anáforas sirven para insistir en las súplicas, pidiendo a Dios misericordia o piedad. Sin embargo, en Juan Ramón Jiménez el sujeto no pide piedad ni intercesión. Desea ser, él mismo, el intemediario para los demás en el conocimiento de las cosas, en su búsqueda de lo metafísico, de lo supremo, de lo más espiritual. Como es poeta, desea recibir el don de la palabra. Así, la poesía es una tentativa de aproximarse a lo absoluto por medio de símbolos

${ }^{10}$ Los poemas citados vienen de Jiménez (1970, 1981, 1993). 
(Ricardo Gullón 1958: 107-108) y de la poesía, y no por medio de una sumisa oración al Dios cristiano. Aunque esto ha de realizarse a través de la Inteligencia, "la poesía se ofrece como una forma de conocimiento no conceptual (...)" y "es una forma de « experimentar » lo que creemos desconocer. Es, por tanto, una forma de conocimiento supradiscursivo", afirma el crítico Blasco Pascual (1982: 277). Las referencias religiosas adquieren así un nuevo sentido. El poeta modifica la poética litánica, la crea de nuevo a su modo, conforme a sus necesidades y objetivos.

El pensamiento religioso de Juan Ramón Jiménez se expresa, de manera especial, mediante su propio concepto de Dios, o más bien de dios, como lo hubiera escrito el mismo poeta. Encontramos un ejemplo muy ilustrativo en el poema 429 (Animal de Fondo), no exento de rasgos litánicos. Recordemos que la búsqueda del ser supremo en el pensamiento poético de Juan Ramón Jiménez no fue, por supuesto, un rasgo aislado. Como recuerda Cardwell, "el Modernismo se distingue por su escepticismo, una falta de fe que tiene sus raíces en el sesgo metafísico negativo de los románticos (...). El escepticismo general finisecular se aumentó frente a los eventos de 1898, la crisis política y social finisecular, una pérdida general de fe y un sentido de alienación de los valores predominantes" (Cardwell 2005: 10).

He aquí la última estrofa del poema:

Eres la gracia libre,

la gloria del gustar, la eterna simpatía,

el gozo del temblor, la luminaria

del clariver, el fondo del amor,

el horizonte que no quita nada;

la trasparencia, dios, la trasparencia,

el uno al fin, dios ahora sólito en lo uno mío,

en el mundo que yo por ti y para ti he creado.

Desde el punto de vista formal, este fragmento es una serie de sintagmas nominales, introducidos por el verbo "ser" en segunda persona: "eres". Por tanto, todos los versos constituyen una especie de apóstrofe, en tono laudatorio. El dios aquí descrito es: gracia, gloria, simpatía, gozo, luminaria, fondo del amor, horizonte. Empleando, pues, los recursos típicos de la poética litánica, en su versión polionímica, el poeta enumera equivalentes del nombre de dios. Observemos que los primeros cinco versos parecen estar de acuerdo con la visión cristiana de Dios. Aunque no son fórmulas recopiladas de letanías, tanto por su poética como por el sentido, podrían aplicarse a una oración cristiana, siendo una modificación individual de la oración litánica. ${ }^{11}$ Sin embargo, los versos siguientes no nos dejan establecer tal interpretación. El hombre se muestra creador: no es un hombre ante su Creador, todopoderoso y digno de alabanza, como lo veríamos en una letanía en

\footnotetext{
11 Más sobre la imagen del mundo del género de la letanía, relacionada con la fe cristiana, véase Sadowski (2011: 12-16).
} 
versión ortodoxa. ${ }^{12} \mathrm{Al}$ revés, es el poeta el que crea el mundo para su dios, escrito con minúscula. Crear belleza, en la filosofía juanramoniana, diviniza al hombre. Así, -conviene subrayarlo- para hablar de lo divino del ser humano, el poeta echa mano del género de la letanía, desde hace siglos relacionado con lo religioso. De esta manera se pronuncia en oposición a la imagen del mundo arraigada en el género.

En el poema Iberia (del tomo Diario de un poeta recién casado) encontramos procedimientos parecidos. He aquí la primera de las tres estrofas:

¡Iberia de oro, que entreveo ya en la bruma,

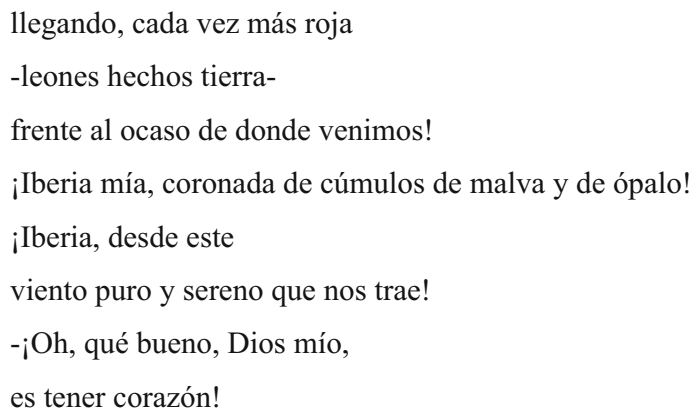

En las perífrasis de Iberia, en función de apóstrofes, se entrelaza el tono solemne con la expresión de las sensaciones subjetivas y sensuales. Lo sensorial se manifiesta gracias a los verbos y sustantivos que se refieren a los sentidos, sobre todo la vista: "entreveo", "rojo", "cúmulos de malva y de ópalo", "viento puro y sereno". Los dos últimos versos se dirigen a Dios, que aquí no aparece en función de receptor de las perífrasis litánicas. Los versos litánicos hablan de Iberia y no de Dios ni de los santos. A consecuencia de este procedimiento poético, es la patria la que adquiere rasgos divinos, aunque descritos en tono subjetivo e individualista. Así, el ansia de transcendencia se expresa por un mundo muy sensorial. Los significados que aporta el género de la letanía poética conducen hacia la sacralización de lo profano.

Los elementos litánicos se muestran particularmente útiles cuando el sujeto lírico desea expresar la complejidad de su identidad: se siente desintegrado e incapaz de encontrar su propia identidad. En el conocido poema "[Yo no soy yo]" (el poema 422 del tomo Eternidades) las enumeraciones litánicas se refieren al yo poético, que parece ir descubriéndose a sí mismo. Lo hace como lo hacía el sujeto de la letanía tradicional refiriéndose a un Dios cuyo nombre desconocía, por lo que no podía describirlo con palabras:

\footnotetext{
$\overline{12}$ Véase también el poema "El nombre conseguido de los nombres" (Animal de fondo).
} 
Yo no soy yo.

Soy éste

que va a mi lado sin yo verlo;

que, a veces, voy a ver,

y que, a veces, olvido.

El que calla, sereno, cuando hablo,

el que perdona, dulce, cuando odio,

el que pasea por donde no estoy,

el que quedará en pie cuando yo muera

Lo que aquí parece fiel a la poética litánica, a nivel formal, son las anáforas en las oraciones adjetivas: "que...", "el que...". Por supuesto, estos recursos empleados en la versión tradicional de las letanías, se referían especialmente a Dios, a la Virgen María o a los santos. Aquí la poética litánica sirve para buscar una identidad propia, a través de varios intentos de describirla. ${ }^{13}$ La repetida estructura típica de la letanía: "el que..." demuestra la imposibilidad de describirse a sí mismo. En lugar de Dios, vemos, pues, al hombre que puede simbolizar a todos. Solo si percibimos los elementos litánicos, podemos apreciar este importante cambio. Del carácter divino del yo poético de Juan Ramón Jiménez habla el crítico Juan de la Cruz Ramos, lo que vendría a demostrar la veracidad de nuestra observación: "El yo juanramoniano que preña todos sus libros es un pronombre universal. Cualquiera es yo. Cualquier lector que quiera es yo. Que se atreva. Divino no es solo Juan Ramón. Divino es cualquier hombre que le lea. Divino es cualquier hombre" (De la Cruz Ramos 2010: 143). El carácter divino del sujeto lírico se demuestra mediante los elementos litánicos empleados por el poeta. ¿Cuál es el resultado? La identidad del hombre se puede describir solo echando mano a paradojas que demuestran la falta de unidad y sentido en la realidad que nos rodea. Otra vez la visión del mundo se opone a la visión cristiana, plasmada en el modelo tradicional del género de la letanía, en el que el Dios constituye la garantía del orden y del sentido del mundo para el hombre.

13 Estas realizaciones recuerdan a las del poeta portugués Fernando Pessoa. Por ejemplo, unos versos de "Poema em linha recta" dicen así:

Eu, que tantas vezes me sinto tâo real como uma metáfora,

Como uma frase escrita por um doente no livro da rapariga qeu encontrou no terraço,

Ou uma partida de xadrez no convés dum transatlântico,

Eu, a ama que empurra os perambulators en todos os jardins públicos,

Eu, o polícia que a olha, parado para trás na álea,

$\mathrm{Eu}$, a criança no carro, que acena a sua inconsciência lúcida com um coral com guizos. [...]

$\mathrm{Eu}$, o que os espera a todos em casa,

$\mathrm{Eu}$, o que eles encontram na rua,

$\mathrm{Eu}$, o que eles nâo sabem de si próprios [...]. 
La interpretación del poema sin poner de relieve los elementos litánicos omite importantes significados que saltan a la vista en la lectura aquí presentada. La visión del mundo relacionada con el género de la letanía hace que todas las referencias religiosas adquieran un significado dominante. Así, lo profano adquiere un significado de lo sacro. Juan Ramón Jiménez descubre la divinidad dentro de sí porque puede hablar de ella gracias a la palabra bella, exacta que es capaz de crear.

También cuando el yo poético intenta describir su alma, la letanía poética resulta insustituible. En el poema "Es mi alma" encontramos estrofas de cuatro versos que siguen el mismo paralelismo sintáctico, repetido a lo largo del poema. Citemos las dos primeras estrofas:

No sois vosotras, ricas aguas

de oro las que corréis

por el helecho, es mi alma.

No sois vosotras, frescas alas

libres, las que os abrís

al iris verde, es mi alma.

Mediante las negaciones, el sujeto lírico intenta acercarse a su propio modo de existir, a lo esencial de su propio ser, como si quisiera entenderse a sí mismo. Este método recuerda la tradición apofática (negativa) en la teología la cual es una tradición antigua pero, para el hombre moderno, sorprendentemente actual. A partir de las experiencias místicas, dicha tradición afirma que de Dios podemos decir solo lo que no es, dado que el conocimiento humano siempre se basa en sus propios conceptos y términos, siendo, por tanto, limitado. Nuestra imaginación, condicionada por nuestra humana percepción, no es capaz de crear la imagen de Dios tal y como es. ${ }^{14}$ Así, para describir el alma humana el poeta recurre a los elementos litánicos, divinizando lo humano.

No solo el yo poético, sino también su vida es el objeto de la descripción litánica. En el poema 33 (Poesía), compuesto de dos estrofas, encontramos las perífrasis que se refieren a su vida:

\footnotetext{
${ }^{14}$ Véase también, por ejemplo, el poema Mi triste ansia, con una estructura parecida, basada en paralelismos y negación.
} 
¡Esta es mi vida, la de arriba,

la de la pura brisa,

la del pájaro último,

la de las cimas de oro de lo oscuro!

¡Esta es mi libertad, oler la rosa,

cortar el agua fría con mi mano loca,

desnudar la arboleda,

cojerle al sol su luz eterna!

La complejidad de la experiencia se expresa por el paralelismo en cada una de las dos estrofas: en la primera estrofa, en la repetición de la estructura sintáctica "la de..."; en la segunda estrofa, en la repetición de los infinitivos. La enumeración de los sintagmas nominales o verbales constituye una serie de perífrasis de la vida y de la libertad. La imagen es metafórica y lírica, y a la vez está compuesta de detalles sin mucha importancia que reflejan una realidad de sensaciones sensuales: una brisa, un pájaro, el olor de una rosa, la luz del sol... Hablar de cosas tan efímeras y fugaces constituye un cambio significativo en el uso del género.

Para describir la subjetividad y el carácter único de una relación Juan Ramón Jiménez también recurre a la poética litánica. En el poema "El ocaso alegre" (Cinco poemas ofrecidos a Lope de Vega) encontramos un ejemplo ilustrativo e interesante:

\section{La armonía toca}

a que yo rompa la sombra,

a que yo coja

tu rosa.

La corriente tiembla

a que yo duerma mi tierra,

a que yo prenda

tu estrella.

El poema reproduce la situación, típica de las letanías, en la que una persona se dirige a la otra. ${ }^{15}$ El objeto de la descripción -podemos interpretarlo así- es la relación del hombre con el ocaso personificado. Gracias al paralelismo sintáctico (en la misma estructura sintáctica repetida en todas las estrofas cambian solo los verbos y los sustantivos) se dejan ver varios aspectos de la misma relación. ${ }^{16}$ Como en la letanía, la relación se puede describir sin fin, inventando metáforas

\footnotetext{
15 Más sobre la situación comunicatica en el género de letanía, véase Sadowski (2011: 93-110). El crítico comenta aquí también la función del autor interior, así como da una interpretación de fórmulas propias de la letanía-oración, lo cual ayuda a entender quién y a quién habla en la letanía como género literario.

16 Véase también, por ejemplo, el poema V de Jardines lejanos.
} 
infinitamente, ya que lo esencial de la relación, otra vez a modo de letanía, siempre queda oculto y misterioso. La letanía, entendida así, es un instrumento importante para buscar la esencia no tanto de las cosas, sino más bien de lo humano. Así lo hemos observado también en otras realizaciones, antes citadas.

Para concluir, el poeta se refiere a la poética presente en la tradición literaria desde hace siglos para expresar otros significados, especialmente relacionados con su mundo interior y también más pertenecientes ya a su época. Juan Ramón Jiménez echa mano del género de la letanía para hablar de las divinas capacidades del poeta, para hablar de lo divino del hombre, para encontrar su propia identidad, para intentar decir lo inefable. Así, la búsqueda juanramoniana de la palabra exacta se realiza a través de la poética litánica y, propia de ella, la abundancia de palabras. El poeta, deseando decir lo inexpresable, recurre a la tradición litánica, cuyo objetivo era intentar llamar con el nombre adecuado lo que se escapa a las palabras del hombre, es decir, sobre todo, a Dios y su santidad. Son diversos los recursos realacionados con la poética litánica que emplea el poeta: antonomasias, perífrasis, paralelismos sintácticos, anáforas y otros tipos de repeticiones. Los rasgos característicos de la poética litánica de Juan Ramón Jiménez le sirven para contemplar la realidad, mirándola desde varias perspectivas, para describir la conciencia del hombre contemporáneo y para describir a su dios (mantengamos la ortografía del poeta). Así, el yo lírico, en muchas ocasiones adquiere rasgos divinos, mientras que el dios ya no es idéntico al Dios cristiano, sino que parece tener más rasgos humanos.

Según hemos visto por los poemas analizados, las realizaciones del poeta español no son negaciones de la tradición ni poemas al revés, como lo fue, por ejemplo, el poema Les litanies de Satan de Baudelaire. No son tampoco religiosos en sentido tradicional. ${ }^{17}$ En muchos casos, la visión del mundo es distinta o incluso opuesta a la que está arraigada en la tradición del género. Sin embargo, el mundo presentado no es desacralizado, porque las referencias a la poética litánica actualizan significados religiosos. Así el poeta realiza su concepción de la poesía como actividad espiritual. ${ }^{18}$ Por lo tanto, los ejemplos presentados demuestran una continuidad de la tradición litánica y nuevas posibilidades expresivas del género: solamente gracias a las referencias a la poética litánica se pueden explicar y se puede leer su significado. Así que ahora, póngamoslo de relieve, en vez de la humillación, el hombre percibe la complejidad de la realidad y su ambigüedad, que se escapa a sus conceptos y términos. La letanía poética da lugar a sensaciones subjetivas y sensuales, y de este modo lo profano adquiere un sentido sagrado. En esto se halla la viveza y la actualidad de la poética litánica de Juan Ramón Jiménez. Y, añadamos, también de muchos otros poetas, como, por ejemplo, de Miguel de Unamuno o García Lorca.

\footnotetext{
17 De las tres tradiciones presentes en la historia del género y mencionadas al principio como genes, especialmente la polionímica juega un papel importante en la obra del poeta. Recordemos que los significados relacionados con otros dos genes -el griego "chaire" y el gen ektenial (súplicas para pedir misericordia o piedad)- prácticamente no aparecen.

18 Cf. Blasco (2010): 41.
} 
Open Access This article is distributed under the terms of the Creative Commons Attribution 4.0 International License (http://creativecommons.org/licenses/by/4.0/), which permits unrestricted use, distribution, and reproduction in any medium, provided you give appropriate credit to the original author(s) and the source, provide a link to the Creative Commons license, and indicate if changes were made.

\section{Bibliografía}

Blasco, J. (2010). Introducción. In J. R. Jiménez Antología poética. Madrid: Cátedra.

Blasco Pascual, F. J. (1982). La poética de Juan Ramón Jiménez. Desarrollo, contexto y sistema. Salamanca: Universidad de Salamanca.

Cardwell, R. A. (2005). Juan Ramón Jiménez y el modernismo: una nueva visión de conjunto. Ínsula, 705, 9-12.

De la Cruz Ramos, J. L. (2010). Saber el infinito. Leer a Juan Ramón Jiménez en un permanente ejercicio de intertextualidad poética. Epos: Revista de filología, 26(2010), 141-154.

Fiore, A. (2012). Juan Ramón Jiménez, de la crisis religiosa al modernismo teológico. Boletín de la Real Academia de Extremadura de las Letras y las Artes, 20(2012), 489-537.

Fradejas Lebrero, J. (1981). La poesía litánica antes de Berceo. Actas de las Terceras Jornadas Berceanas. Logroño (n.d.).

Fradejas Lebrero, J. (1988). La forma litánica en la poesía popular. Lección inaugural curso 1988-89. Madrid: UNED.

Fradejas Lebrero, J. (1996). La forma litánica en la poesía del siglo XX. Revista Literaria LVIII, 116, 399-425.

Gullón, R. (1958). Conversaciones con Juan Ramón. Madrid: Taurus.

Hambrook, G. (1985). The influence of Charles Baudelaire in Spanish Modernismo. Nottingham: Nottingham University.

Jiménez, J. R. (1970). Tercera antolojía poética. Madrid: Editorial Biblioteca Nueva.

Jiménez, J. R. (1981). Dios deseado y deseante (Animal de fondo). Madrid: Taurus.

Jiménez, J. R. (1993). Antología poética. Madrid: Cátedra.

López Castro, A. (2006). Juan Ramón Jiménez: hacia una poética de la levedad. Revista de filología de la Universidad de La Laguna, 24(2006), 167-186.

Marín Hernández, D. (2007). La recepción y traducción de "Les Fleurs du Mal” en España. Málaga: Miguel Gómez Ediciones.

Medina Arjona, E. (2009). Lectura. Recepción de Baudelaire en España. Rapsoda. Revista de Literatura, $1,120-134$

Sadowski, W. (2011). Litania i poezja. Varsovia: Wydawnictwo Uniwersytetu Warszawskiego.

Torres Villarroel, D. (1798). Libro primero Vida ejemplar de la venerable madre Gregoria Francisca de Santa Teresa. Madrid: Imprenta de la Viuda de Ibarra. 